\title{
Primary MiNEN of the urinary bladder: an hitherto undescribed entity composed of large cell neuroendocrine carcinoma and adenocarcinoma with a distinct clinical behavior
}

\author{
Description of a case and review of the pertinent literature
}

Giacomo Maria Pini ${ }^{1} \cdot$ Silvia Uccella ${ }^{1}$ (D) $\cdot$ Matteo Corinti $^{2} \cdot$ Maurizio Colecchia $^{3} \cdot$ Giuseppe Pelosi $^{4,5} \cdot$ Carlo Patriarca $^{6}$

Received: 13 November 2020 / Revised: 28 December 2020 / Accepted: 6 January 2021 / Published online: 17 January 2021

(C) The Author(s) 2021

\begin{abstract}
Neuroendocrine carcinomas (NECs) of the urinary bladder are very rare and can be observed in the context of mixed neuroendocrine/non-neuroendocrine neoplasms (MiNENs), most frequently in association with urothelial carcinoma. Small cell NECs are far more common than large cell NECs (LCNECs), which are exceedingly rare. We describe a primary MiNEN of the urinary bladder, composed of a LCNEC and of an adenocarcinoma, in which the neuroendocrine component reached complete pathological regression after neoadjuvant M-VAC chemotherapy, whereas the nonneuroendocrine component of the tumor progressed to metastatic disease. Compared to mixed neuroendocrine/nonneuroendocrine neoplasms described in the literature until now, this appears to be a unique case that expands the spectrum of neuroendocrine neoplasia of the urinary bladder.
\end{abstract}

Keywords Neuroendocrine neoplasm · Neuroendocrine carcinoma $\cdot$ Mixed neuroendocrine/non-neuroendocrine neoplasm · Urinary bladder

\section{Introduction}

Neuroendocrine neoplasms (NENs) of the urinary bladder represent less than $1 \%$ of all malignancies in this site and are mainly represented by neuroendocrine carcinoma (NEC), whereas well-differentiated neuroendocrine tumors (NETs) are only anecdotally reported [1]. A significant proportion of NECs of the urinary bladder contains a

Silvia Uccella

silvia.uccella@uninsubria.it

1 Department of Medicine and Surgery, Unit of Pathology, University of Insubria, via O. Rossi 9, 21100 Varese, Italy

2 Department of Urology, ASST Lariana, Como, Italy

3 Department of Pathology, Fondazione IRCCS Istituto Nazionale dei Tumori, Milan, Italy

4 Department of Oncology and Hemato-Oncology, University of Milan, Milan, Italy

5 Inter-Hospital Pathology Division, IRCCS MultiMedica, Milan, Italy

6 Department of Pathology, ASST Lariana, Como, Italy non-neuroendocrine component, mostly represented by urothelial carcinoma and, more rarely, by squamous cell carcinoma or adenocarcinoma, and can be designated as mixed neuroendocrine/non-neuroendocrine neoplasms (MiNENs) in analogy to similar neoplasms arising in the digestive system [2]. Among vesical NECs, small cell NECs (SCNECs) are more frequently diagnosed than large cell NEC (LCNEC) [2,3].

Here, we present a case of a MiNEN of the urinary bladder in which the neuroendocrine component, represented by a LCNEC, underwent complete pathological regression after neoadjuvant chemotherapy, while the non-neuroendocrine portion persisted and spread to metastatic sites.

\section{Case history}

A 49-year-old man was referred to the Urology Department for self-limiting painless gross hematuria in March 2018. Urinary cytology was positive for malignant epithelial neoplastic cells. Contrast-enhanced computerized tomography (CECT) showed a 46-mm-wide lesion 


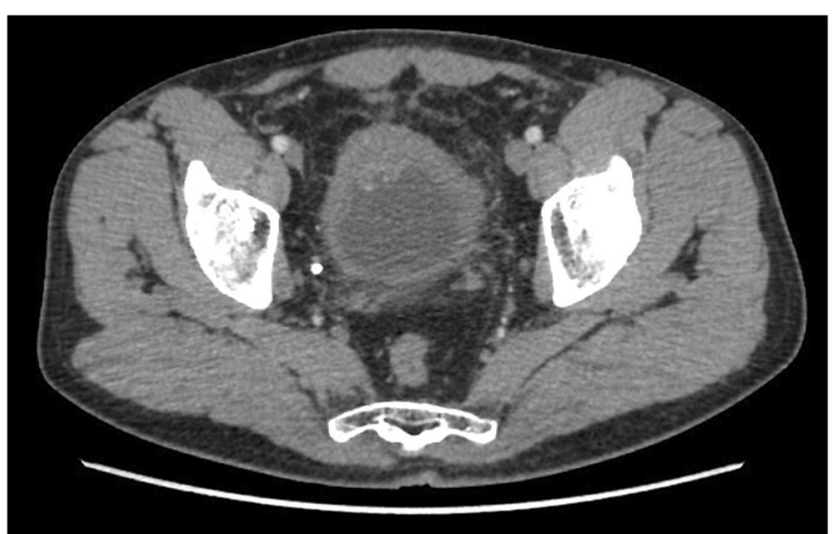

Fig. 1 Contrast-enhanced computerized tomography (CECT) of the bladder: Contrast-enhanced computed tomography revealed a 46-mm lesion on the dome of the bladder, with concomitant thickening of the bladder walls

located on the dome of the bladder (Fig. 1). Transurethral resection of the bladder (TURB) was then performed, and the specimen was sent to the Pathology service. A diagnosis of MiNEN composed of LCNEC and adenocarcinoma of the bladder was signed out. Computed tomography of the brain, chest, and abdomen did not show metastatic disease. The patient received 3 cycles of neoadjuvant chemotherapy (methotrexate, vinblastine, adriamycin, and cisplatin-MVAC).

Radical cystoprostatectomy combined with the removal of pelvic and obturator lymph nodes was performed and a muscle-invasive poorly differentiated adenocarcinoma was reported, with no evidence of residual LCNEC. Three magnetic resonance imaging (MRI) scans of the abdomen were performed for clinical re-staging in January, May, and
September 2019, respectively, without any evidence of relapse or metastatic disease.

In late November 2019, a growing lump on the penis and right epididymis was biopsied, revealing a poorly differentiated adenocarcinoma, without a neuroendocrine component. Emasculation was performed. After 2 years and 2 months after initial diagnosis, the patient is alive with ultrasonographic evidence of residual metastatic disease in inguinal lymph nodes.

\section{Materials and methods}

\section{Morphology and immunohistochemistry}

Tissue samples obtained from the different specimens (i.e., TURB, radical cystoprostatectomy, and percutaneous biopsy of the epididymis) were fixed in buffered formalin and routinely processed to paraffin wax. Five-micrometer-thick sections were routinely stained with hematoxylin and eosin and Alcian-PAS stain.

The immunohistochemical study was performed on additional 3- $\mu \mathrm{m}$-thick sections using prediluted ready-to-use vials of the antibodies listed in Table 1 with an automated immunostainer (BenchMark Ultra, Ventana Roche Diagnostics) and standardized protocols (Ventana OptiView DAB IHC Detection Kit).

\section{Review of the literature}

The Pubmed database of the National Center for Biotechnology Information (NCBI) of the U.S. National
Table 1 Antibodies used for immunohistochemical analysis

\begin{tabular}{lll}
\hline Antibody & Manufacturer & Clone \\
\hline CD56 & Cell Marque Corporation* $^{*}$ & MRQ-42 \\
CDX2 & Ventana $^{\circ}$ & EPR2764Y \\
Carcinoembrionic antigen (CEA) & Ventana $^{\circ}$ & CEA31 \\
Chromogranin & Ventana $^{\circ}$ & LK2H10 \\
CK Cam5.2 & Ventana $^{\circ}$ & CAM5.2 \\
CK20 & Ventana $^{\circ}$ & SP33 \\
GATA3 & Cell Marque Corporation* $^{*}$ & L50-823 \\
Ki-67 & Ventana $^{\circ}$ & $30-9$ \\
p16 & Ventana $^{\circ}$ & CINtec® p16 histology \\
p53 & Ventana $^{\circ}$ & Confirm \\
p63 & anti-p53 (DO-7) \\
Rb1 & Ventana $^{\circ}$ & 4 A4 \\
Synaptophysin & BD Biosciences $^{\S}$ & G3-245 \\
TTF1 & Ventana $^{\circ}$ & SP11 \\
\hline
\end{tabular}

*Cell Marque Corporation, Rocklin, CA, USA

${ }^{\circ}$ Ventana Medical Systems Inc., Tucson, AZ, USA

${ }^{\S}$ BD Biosciences, San Jose, CA, USA 
Fig. 2 Neuroendocrine carcinoma in vesical biopsy: Low $(\mathbf{a}$, hematoxylin-eosin, $\times 50)$ and intermediate (b, hematoxylineosin, $\times 200$ ) magnification showing solid, trabecular, and insular growth of large neoplastic cells. Zonal necrosis is also present. Immunohistochemical stains show positivity for general neuroendocrine markers (synaptophysin (c) and chromogranin A (d)). Ki67 proliferation index is very high (e) and tumor cells show hyperexpression of p16 (f) and p53 (g), whereas Rb1 expression is lost (h) (immunoperoxidase, $\times$ 200)
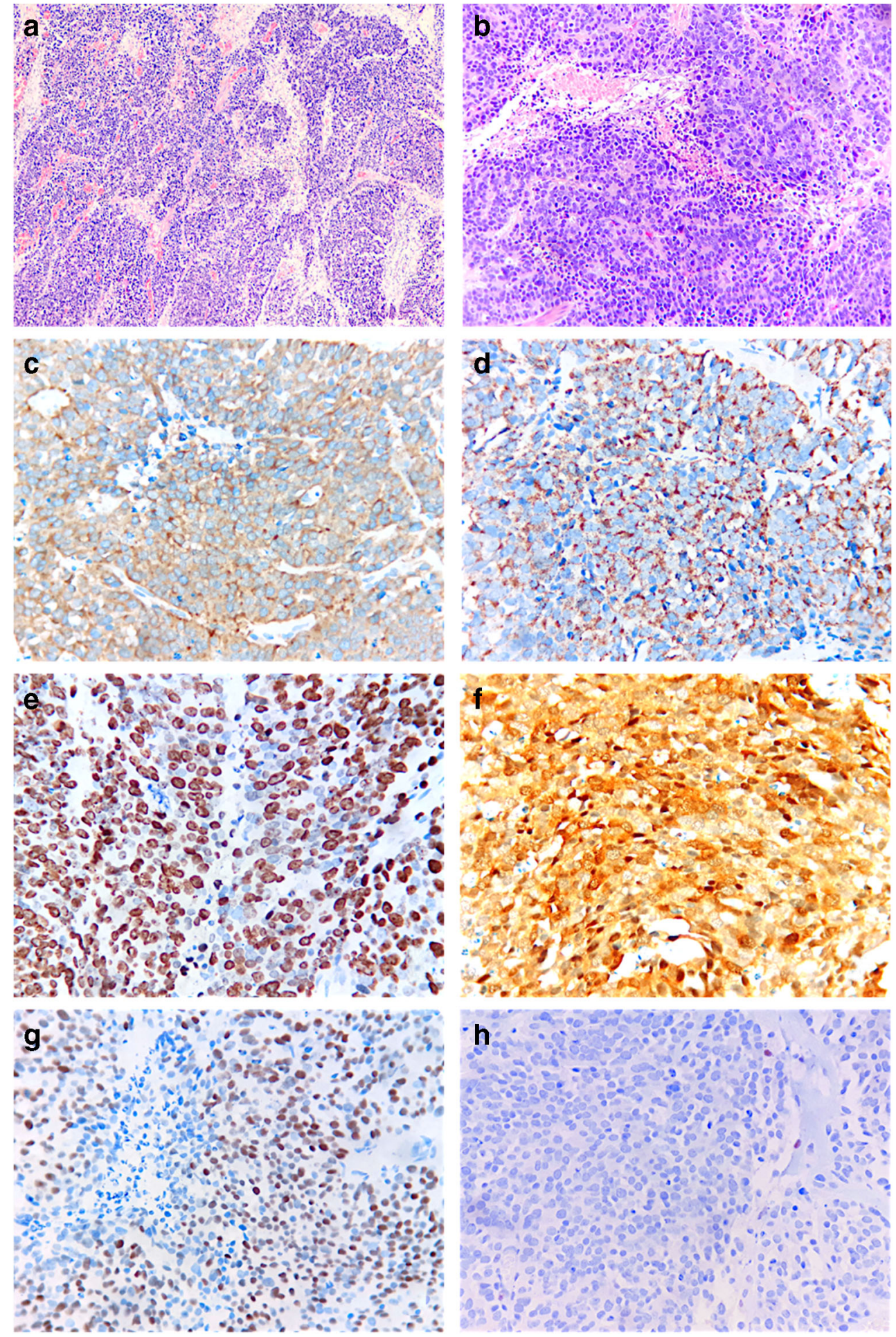

Library of Medicine was searched using the following string "large cell neuroendocrine carcinoma [AND] urinary bladder." All articles written in English were included. For each article, the reported cases were identified and, for each case, the following parameters were considered: age, sex, symptoms, presence of non-neuroendocrine component, immunophenotype, treatments, and outcome.

\section{Results}

\section{Morphology and immunohistochemistry}

The TURB specimen was entirely processed for microscopical analysis. Most of the specimens (70\% of the total neoplastic volume) featured muscle-infiltrating neoplastic 
Fig. 3 Adenocarcinoma in vesical biopsy: Low (a, hematoxylin-eosin, $\times 20)$ and high (b, hematoxylin-eosin, $x$ 400) magnification of papillary and gland-like structures of neoplastic cells with polarized nuclei

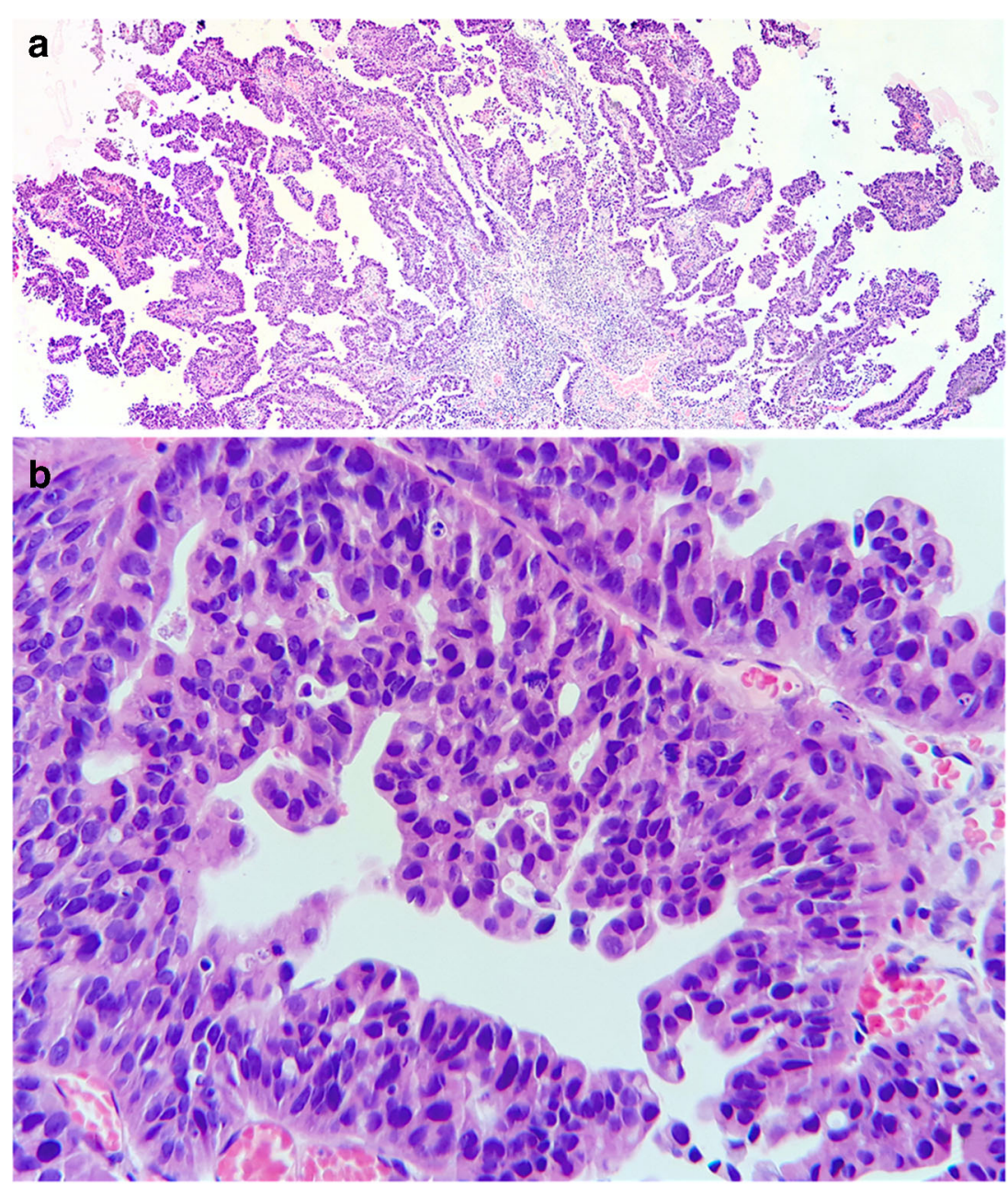

proliferation with organoid architecture, showing zonal necrosis (Fig. 2a). Neoplastic cells had moderately abundant, lightly eosinophilic cytoplasm, large vesicular nuclei, and focally prominent eosinophilic nucleoli. Apoptotic bodies were abundant and mitotic index was 40/10 high-power fields (HPFs) (Fig. 2b). Immunostains (Fig. 2c-h) were positive for Synaptophysin, Chromogranin A, CD56, CK Cam5.2, and, focally, for CK20 and TTF1. CDX2, GATA3, and p63 were negative. Intense cytoplasmic and nuclear p16 signal was also present, as well as p53 hyperexpression, whereas Rb1 expression was lacking. Ki67-related proliferative index was $85 \%$.

The residual $30 \%$ of the total neoplastic volume was composed of an adenocarcinoma (Fig. 3), which was partially admixed with the former, but showed a tendency to be located in the most superficial layers of the bladder mucosa. Mitotic index was 4/10 HPFs. Immunostains for Synaptophysin, Chromogranin A, CD56, CEA, and p63 were negative, whereas those for CK Cam5.2, CK20, and GATA3 were diffusely positive and CDX2 was zonally expressed. Scattered cells were positive for TTF1. Rb1 was focally positive, while p16 and p53 had the same expression pattern as the neuroendocrine component. The final diagnosis was of muscle- invasive primary urinary bladder MiNEN, composed of LCNEC (70\%) and moderately differentiated adenocarcinoma $(30 \%)$.

The radical cystoprostatectomy specimen did not show, at gross evaluation, any residual neoplastic mass in the bladder. Microscopically, an estimated $90 \%$ of the vesical wall showed fibrosis and chronic inflammation with giantcell granulomas. In the remaining $10 \%$, residual poorly differentiated adenocarcinoma was present, showing discohesive atypical cells with signet-ring-like and lipoblast-like features (Fig. 4). p63 and, focally, GATA3 were positive, but TTF1, CDX2, Chromogranin A, Synaptophysin, and $\mathrm{Rb} 1$ were absent. No residual LCNEC was identified.

In the percutaneous needle biopsy of the epididymis, poorly differentiated adenocarcinoma infiltrating fibromuscular tissue was seen (Fig. 5). Heterogenous positivity for GATA3 and p63 and negative stains for Chromogranin A, Synaptophysin, CD56, CD138, and PSA were observed. No evidence of LCNEC was found. The same morphological and IHC characteristics were observed in the specimen obtained from emasculation. 
Fig. 4 Vesical bladder surgical specimen: Poorly differentiated adenocarcinoma composed of discohesive signet-ring-like cells (a, hematoxylin-eosin, $\times 630$ ), with intense positivity for Alcian blue (b, AB-PAS stain, $\times$ 630)
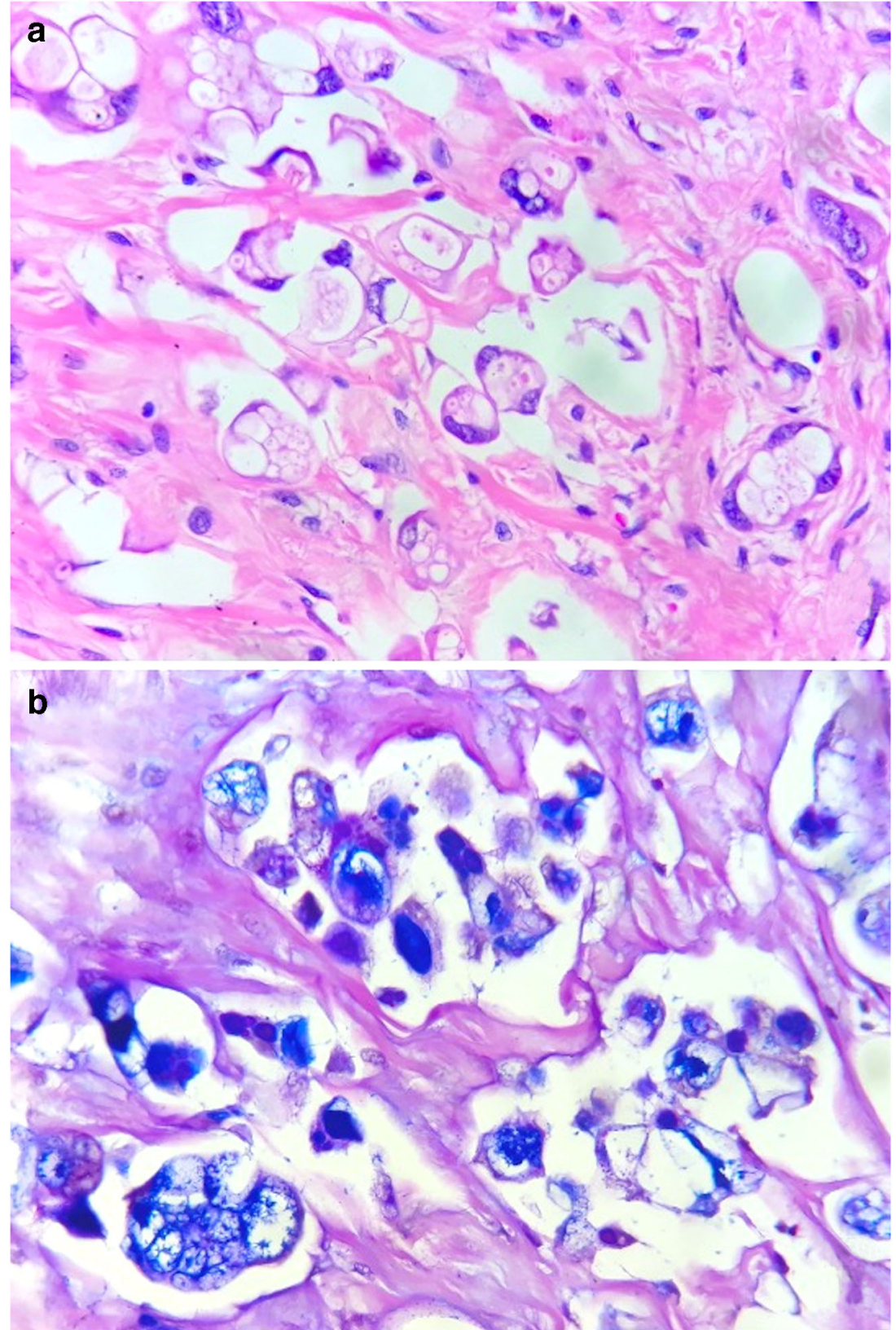

\section{Review of the literature}

We identified 25 articles published between 1986 and 2020, reporting a total of 41 cases of LCNEC of the urinary bladder (Table 2) [4-28]. The male-to-female ratio was $36: 5$ and patients' age at diagnosis ranged from 20 to 84 years, with a median of 61 years. Specifically, 23 cases (56.1\%) were pure LCNEC, 7 cases $(17.1 \%)$ were a combined SCNEC/LCNEC [20, 23], 1 case $(2.4 \%)$ had sarcomatous components [8], and 10 cases (24.4\%) showed epithelial non-neuroendocrine components. Overall, the amount of the epithelial non-neuroendocrine components was small: in two cases, it was reported to account for less than $2 \%$ and less than $5 \%$, respectively $[6,20]$; in the remaining cases, a descriptive report was given (i.e., "evidence of,"
[9] "some foci of," [13] or "minor contributions of" [16] epithelial non-neuroendocrine component).

Surgery and chemotherapy were the most frequently adopted treatments. Neoplasms were frequently muscle invasive, with or without fat infiltration, and commonly metastatic to regional lymph nodes. Outcomes were quite varied and based on follow-ups of different lengths.

\section{Discussion}

Our case is a rare example of what can be called a true MiNEN of the urinary bladder, as two morphologically distinct components, intimately admixed, one neuroendocrine and the 
Fig. 5 Epididymal biopsy: Poorly differentiated adenocarcinoma infiltrating with an "Indian file" pattern $(\mathbf{a}$, hematoxylin-eosin, $\times$ 200), immunoreactive for GATA 3 (b, immunoperoxidase, $\times 200$ )
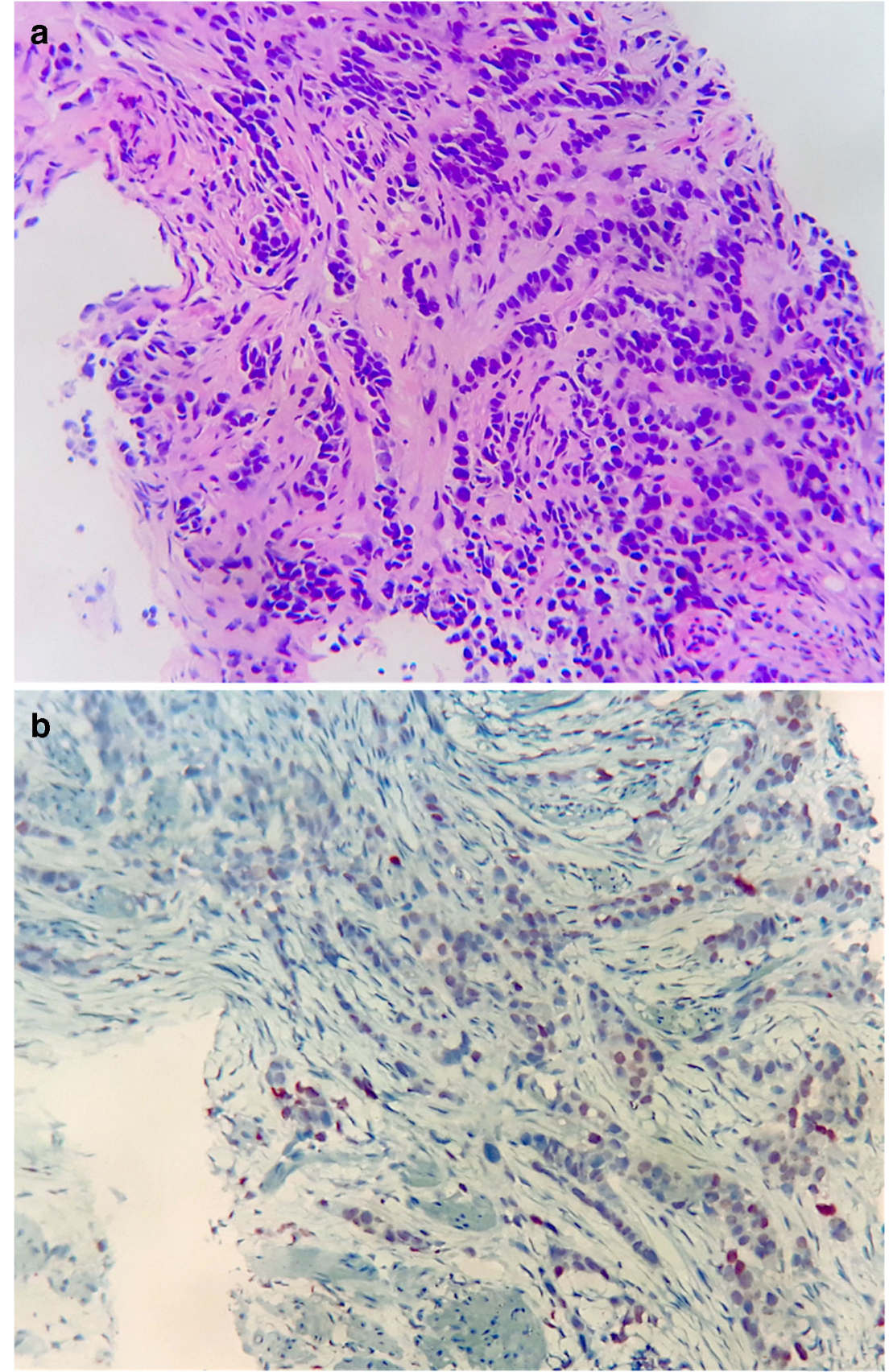

other non-neuroendocrine, were evident, both morphologically and immunohistochemically. In addition, this case is strictly adherent to the criteria used for digestive MiNENs [3], as each component represented at least $30 \%$ of tumor mass. In contrast, in previously reported cases of mixed vesical LCNECs, only a minor non-neuroendocrine component was detected [6, $9,13,16,20]$. Indeed, the adoption of a $30 \%$ cutoff is not based on clinical evidence, but rather it was arbitrarily introduced to avoid overestimating the biological relevance of focal cells with a divergent differentiation, which would be unlikely to influence the overall prognosis [29]. Nevertheless, as it has been underlined elsewhere [2, 29], we believe that minor, but morphologically recognizable, neoplastic components with divergent differentiation must be recorded in the pathological report, above all when they are morphological high-grade, because they still may influence prognosis and need a specific management.

LCNECs of the urinary bladder are exceptionally rare tumors, with only 41 cases reported in the literature (Table 1). Given their rarity, the exclusion of vesical metastatic disease from an unknown primary site is of paramount importance. Clinical and radiological information is pivotal in this task, as immunohistochemical markers have poor reliability in the identification of the primary sites of NECs [30]. In our case, 


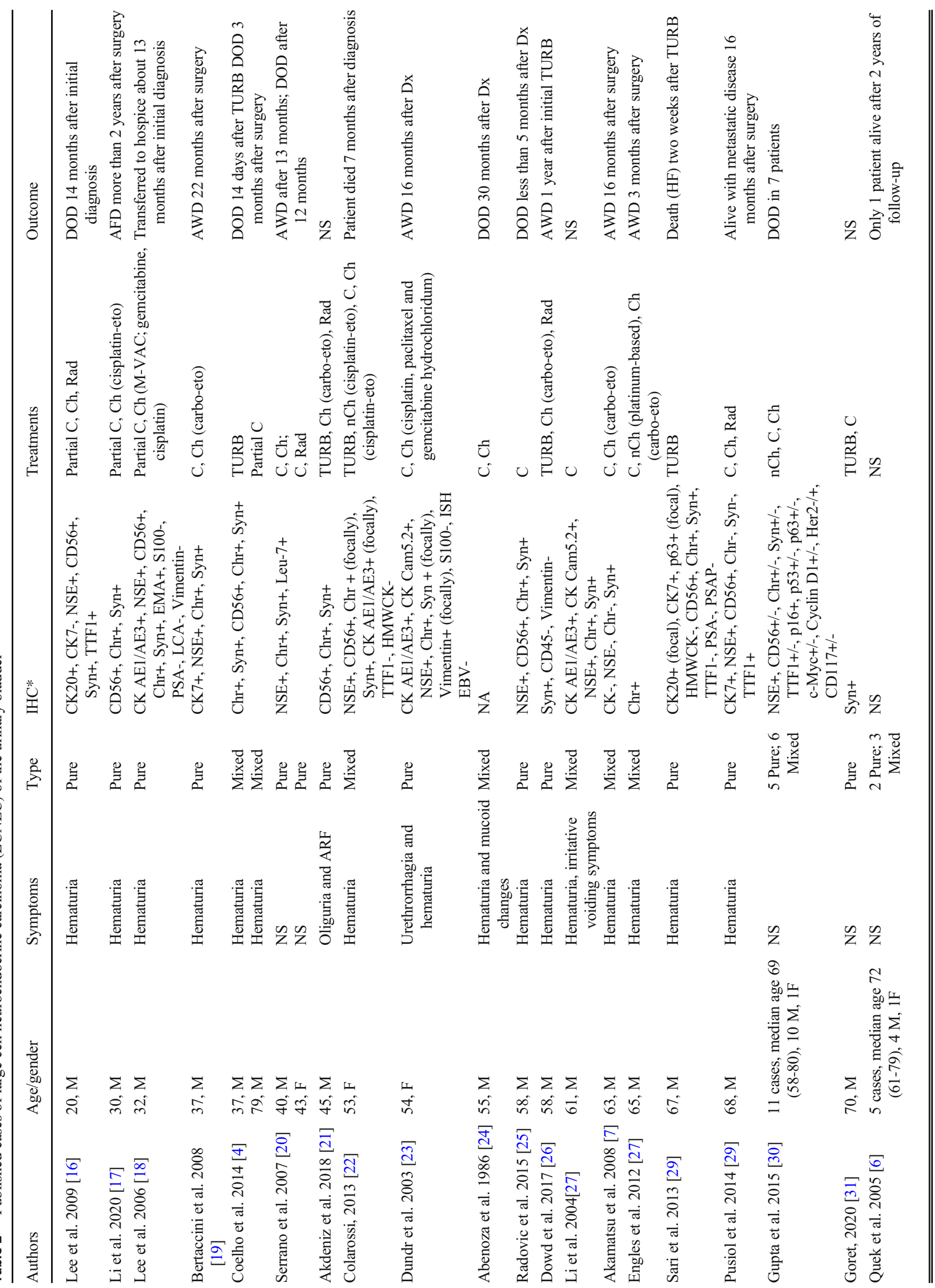


the application of immunohistochemistry for general neuroendocrine markers on the TURB sample highlighted the neuroendocrine component of the vesical neoplasm and allowed to negatively detect the non-neuroendocrine component. As expected, transcription factors (TTF1 and GATA3) were not useful in confirming or denying the vesical origin of the LCNEC.

The origin of NECs of the urinary bladder has been tentatively explained by different theories, including the possible derivation of the neoplastic neuroendocrine clone from a common multipotential cancer stem cell shared with nonendocrine carcinoma or its development from normal or metaplastic neuroendocrine cells of the urothelial mucosa [31,32]. Recently, Chang and colleagues provided an elegant demonstration that the genomic alterations present in NECs of the urinary bladder more closely resemble urothelial carcinoma than small cell lung cancers, suggesting an organ-specific rather than a cell type-specific mechanism of cancerogenesis for NECs [33]. This model also explains the pathogenesis of vesical MiNENs and gives details on the molecular pathways involved. In the case of our patient, the non-neuroendocrine component was an adenocarcinoma with heterogeneous morphology across different specimens. It is conceivable that this change in morphology is related to intratumor heterogeneity, possibly enhanced by the selection of a previously unwitnessed neoplastic clone by neoadjuvant chemotherapy.

The morphological heterogeneity of MiNENs is mirrored by their variable prognosis, which, at least in digestive MiNENs including a NEC, seems to be driven by the highgrade neuroendocrine component and to be comparable to that of pure NECs [2]. Intriguingly, in our patient, the adenocarcinomatous dyscohesive component was revealed to be the most aggressive part of the MiNEN, persisting after neoadjuvant chemotherapy and giving rise to metastatic localizations. In contrast, the NEC component responded well to chemotherapy and did not recur. In fact, the M-VAC regimen administered to our patient was specifically chosen on the basis of the histopathological report on the diagnostic biopsy. The importance of a specific therapeutic approach to the NENs of the urinary bladder relies on their clinicopathological features $[30,34]$ and has been strengthened by molecular studies. Indeed, the latest consensus on the molecular subtypes of muscle-invasive bladder cancer identifies a neuroendocrinelike class featuring TP53 and RB1 gene mutations, poorly differentiated neuroendocrine morphology, poor survival, and sensitivity to platinum-based chemotherapy, similar to NECs affecting other organs $[35,36]$. On the basis of this case, it should be considered that, at least in the urinary bladder, non-neuroendocrine cancer can play a pivotal role in the determination of life quality and prognosis even in the setting of the NEC-including MiNEN.

In summary, we have reported a rare, if not unique, case of LCNEC of the urinary bladder, admixed with a high-grade 
carcinomatous component, for which we endorse the term of MiNEN. The correct diagnosis on the preoperatory biopsy allowed the administration of a platinum-based neoadjuvant polychemotherapy to the patient, which was followed by the complete pathological response of the LCNEC component, which did not recur in metastatic sites.

Authors' contributions Giacomo Maria Pini: Conceptualization; investigation; and writing - original draft

Silvia Uccella: Conceptualization; investigation; methodology; project administration; resources; writing - review and editing; and supervision

Matteo Coriniti: Investigation; validation; and visualization

Maurizio Colecchia: Investigation; validation; and visualization

Giuseppe Pelosi: Investigation; validation; and visualization

Carlo Patriarca: Conceptualization; investigation; and supervision

Funding Open Access funding provided by Università degli Studi dell'Insubria.

Data availability All data generated or analyzed during this study are included in this published article

\section{Compliance with ethical standards}

Conflict of interest The authors declare that they have no conflict of interest.

Ethics approval The study has been conducted according to the guidelines of the local ethical committee.

Consent to participate and for publication Informed consent has been obtained from the patient.

\section{Code availability Not applicable}

Open Access This article is licensed under a Creative Commons Attribution 4.0 International License, which permits use, sharing, adaptation, distribution and reproduction in any medium or format, as long as you give appropriate credit to the original author(s) and the source, provide a link to the Creative Commons licence, and indicate if changes were made. The images or other third party material in this article are included in the article's Creative Commons licence, unless indicated otherwise in a credit line to the material. If material is not included in the article's Creative Commons licence and your intended use is not permitted by statutory regulation or exceeds the permitted use, you will need to obtain permission directly from the copyright holder. To view a copy of this licence, visit http://creativecommons.org/licenses/by/4.0/.

\section{References}

1. Moch H, Humphrey PA, Ulbright TM, Reuter VE (2016) WHO Classification of Tumours of the Urinary System and Male Genital Organs, 4th edn. IARC Press, Lyon

2. La Rosa S, Sessa F, Uccella S (2016) Mixed neuroendocrinenonneuroendocrine neoplasms (MiNENs): unifying the concept of a heterogeneous group of neoplasms. Endocr Pathol 27(4): 284-311. https://doi.org/10.1007/s12022-016-9432-9

3. WHO Classification of Tumours. Digestive System Tumours (2019) Fifth Edit. IARC Press, Lyon
4. Abenoza P, Manivel C, Sibley RK (1986) Adenocarcinoma with neuroendocrine differentiation of the urinary bladder. Clinicopathologic, immunohistochemical, and ultrastructural study. Arch Pathol Lab Med 110(11):1062-1066 https://pubmed.ncbi. nlm.nih.gov/3778122

5. Hailemariam S, Gaspert A, Komminoth P, Tamboli P, Amin M (1998) Primary, pure, large-cell neuroendocrine carcinoma of the urinary bladder. Mod Pathol. 11(10):1016-1020 https://pubmed. ncbi.nlm.nih.gov/9796733

6. Evans AJ, Al-Maghrabi J, Tsihlias J, Lajoie G, Sweet JM, Chapman WB (2002) Primary large cell neuroendocrine carcinoma of the urinary bladder. Arch Pathol Lab Med 126(10):1229-1232. https://doi.org/10.1043/0003-9985(2002)126<1229:PLCNCO >2. $0 . \mathrm{CO} ; 2$

7. Dundr P, Pešl M, Povýšil C, Vítková I, Dvořáček J (2003) Large cell neuroendocrine carcinoma of the urinary bladder with lymphoepithelioma-like features. Pathol Res Pract 199(8):559563. https://doi.org/10.1078/0344-0338-00462

8. Li Y, Outman JE, Mathur SC (2004) Carcinosarcoma with a large cell neuroendocrine epithelial component: first report of an unusual biphasic tumour of the urinary bladder. J Clin Pathol 57(3):318 320. https://doi.org/10.1136/jcp.2003.013474

9. Quek ML, Nichols PW, Yamzon J et al (2005) Radical cystectomy for primary neuroendocrine tumors of the bladder: The University of Southern California experience. J Urol 174(1):93-96. https://doi. org/10.1097/01.ju.0000162085.20043.1f

10. Lee KH, Ryu SB, Lee MC, Park CS, Juhng SW, Choi C (2006) Primary large cell neuroendocrine carcinoma of the urinary bladder. Pathol Int 56(11):688-693. https://doi.org/10.1111/j.1440-1827. 2006.02031.x

11. Serrano FA, Sánchez-Mora N, Arranz JA, Hernández C, ÁlvarezFernández E (2007) Large cell and small cell neuroendocrine bladder carcinoma: immunohistochemical and outcome study in a single institution. Am J Clin Pathol 128(5):733-739. https://doi.org/ 10.1309/HTREM6QYQDYGNWYA

12. Bertaccini A, Marchiori D, Cricca A et al (2008) Neuroendocrine carcinoma of the urinary bladder: case report and review of the literature. Anticancer Res. 28(2 B):1369-1372. https://doi.org/10. 1093/oxfordjournals.jjco.a039461

13. Akamatsu S, Kanamaru S, Ishihara M, Sano T, Soeda A, Hashimoto K (2008) Primary large cell neuroendocrine carcinoma of the urinary bladder: case report. Int J Urol 15(12):1080-1083. https://doi.org/10.1111/j.1442-2042.2008.02168.x

14. Lee WJ, Kim CH, Chang SE, Lee MW, Choi JH, Moon KC, Koh JK (2009) Cutaneous metastasis from large-cell neuroendocrine carcinoma of the urinary bladder expressing CK20 and TTF-1. Am J Dermatopathol 31(2):166-169. https://doi.org/10.1097/ DAD.0b013e31818eba4c

15. Tsugu A, Yoshiyama M, Matsumae M (2011) Brain metastasis from large cell neuroendocrine carcinoma of the urinary bladder. Surg Neurol Int 2(1):84. https://doi.org/10.4103/2152-7806.82250

16. Engles CD, Slobodov G, Culkin DJ. Primary mixed neuroendocrine carcinoma of the bladder with large cell component : a case report and review of the literature. 2012:1021-1025. doi:https://doi. org/10.1007/s11255-012-0148-6

17. Hata S, Tasaki Y (2013) A case of the large cell neuroendocrine carcinoma of the urinary bladder. Case Rep Med 2013:2-5. https:// doi.org/10.1155/2013/804136

18. Colarossi C, Pino P, Giuffrida D, Aiello E, Costanzo R, Martinetti D, Memeo L (2013) Large cell neuroendocrine carcinoma (LCNEC) of the urinary bladder: a case report. Diagn Pathol 8(1): 19. https://doi.org/10.1186/1746-1596-8-19

19. Sari A, Ermete M, Sadullahoğlu C, Bal K, BolükbașI A (2013) Large cell neuroendocrine carcinoma of urinary bladder; case presentation. Turk Patoloji Dergisi/Turkish J Pathol 29(2):138-142. https://doi.org/10.5146/tjpath.2013.01165 
20. Coelho HMP, Pereira BAGJ, Caetano PAST (2014) Large cell neuroendocrine carcinoma of the urinary bladder: case report and review. Curr Urol 7(3):155-159. https://doi.org/10.1159/ 000356270

21. Pusiol T, Morichetti D, Zorzi MG (2014) "Pure" primary large cell neuroendocrine carcinoma of the urinary bladder: case report, literature review and diagnostic criteria. Pathologica. 106(2):82-85

22. Radović N, Turner R, Bacalja J (2015) Primary "pure" large cell neuroendocrine carcinoma of the urinary bladder: a case report and review of the literature. Clin Genitourin Cancer 13(5):e375-e377. https://doi.org/10.1016/j.clgc.2015.03.005

23. Gupta S, Thompson RH, Boorjian SA, Thapa P, Herrera Hernandez LP, Jimenez RE, Costello BA, Frank I, Cheville JC (2015) High grade neuroendocrine carcinoma of the urinary bladder treated by radical cystectomy: a series of small cell, mixed neuroendocrine and large cell neuroendocrine carcinoma. Pathology. 47(6):533542. https://doi.org/10.1097/PAT.0000000000000301

24. Chong V, Zwi J, Hanning F, Lim R, Williams A, Cadwallader J (2017) A case of large cell neuroendocrine carcinoma of the bladder with prolonged spontaneous remission. J Surg Case Reports 2017(5):1-4. https://doi.org/10.1093/jscr/rjw179

25. Dowd K, Rotenberry C, Russell D, Wachtel M, De Riese W (2017) Rare occurrence of a poorly differentiated neuroendocrine tumor of the bladder. Case Rep Med 2017(Figure 1):7-11. https://doi.org/10. 1155/2017/4812453

26. Akdeniz E, Bakirtas M, Bolat MS, Akdeniz S, Özer I (2018) Pure large cell neuroendocrine carcinoma of the bladder without urological symptoms. Pan Afr Med J. 30:1-4. https://doi.org/10.11604/ pamj.2018.30.134.13437

27. Goret CC (2020) Neuroendocrine tumors of the urinary bladder: a case series and review of the literature. Ann Ital Chir 91:65-68

28. Li W, Su ZZ, Kang JH, Xie XY, Xie XH, Zhuang BW (2020) Application of contrast-enhanced ultrasonography for large cell neuroendocrine carcinoma in the urinary bladder: a case report. BMC Med Imaging. 20(1):10-14. https://doi.org/10.1186/s12880020-00447-6

29. Uccella S, La Rosa S. Looking into digestive MiNENs: subtypes, prognosis and predictive factors. Histopathology. 2020:0-3. doi: https://doi.org/10.1111/his.14178
30. Uccella S, La Rosa S, Volante M, Papotti M (2018) Immunohistochemical biomarkers of gastrointestinal, pancreatic, pulmonary, and thymic neuroendocrine neoplasms. Endocr Pathol 29(2):150-168. https://doi.org/10.1007/s12022-018-9522y

31. Ghervan L, Zaharie A, Ene B, Elec FI (2017) Small-cell carcinoma of the urinary bladder: where do we stand? Clujul Med 90(1):1317. https://doi.org/10.15386/cjmed-673

32. Cheng L, Jones TD, McCarthy RP et al (2005) Molecular genetic evidence for a common clonal origin of urinary bladder small cell carcinoma and coexisting urothelial carcinoma. Am J Pathol. 166(5):1533-1539. https://doi.org/10.1016/S0002-9440(10) 62369-3

33. Chang MT, Penson A, Desai NB, Socci ND, Shen R, Seshan VE, Kundra R, Abeshouse A, Viale A, Cha EK, Hao X, Reuter VE, Rudin CM, Bochner BH, Rosenberg JE, Bajorin DF, Schultz N, Berger MF, Iyer G, Solit DB, al-Ahmadie HA, Taylor BS (2018) Small-cell carcinomas of the bladder and lung are characterized by a convergent but distinct pathogenesis. Clin Cancer Res 24(8): 1965-1973. https://doi.org/10.1158/1078-0432.CCR-17-2655

34. Helpap B, Klöppel G (2002) Neuroendocrine carcinomas of the prostate and urinary bladder: a diagnostic and therapeutic challenge. Virchows Arch 440(3):241-248. https://doi.org/10.1007/s00428001-0583-8

35. Kamoun A, de Reynies A, Allory Y, et al. A consensus molecular classification of muscle-invasive bladder cancer. SSRN Electron J. 2019:1-14. doi:10.2139/ssrn.3372965

36. Warrick JI, Knowles MA, Yves A, van der Kwast T, Grignon DJ, Kristiansen G, Egevad L, Hartmann A, Cheng L (2020) Report from the International Society of Urological Pathology (ISUP) Consultation Conference on Molecular Pathology of Urogenital Cancers. II. Molecular pathology of bladder cancer: progress and challenges. Am J Surg Pathol 00(00):1-17. https://doi.org/10.1097/ PAS.0000000000001453

Publisher's note Springer Nature remains neutral with regard to jurisdictional claims in published maps and institutional affiliations. 